\title{
Analysis of Shared Services Center Deployment at a University Hospital (CENTROMED) in Natal, Brazil: A Study on Availability and Capacity
}

This article was published in the following Dove Press journal: Journal of Multidisciplinary Healthcare

\author{
Davidson Rogério \\ de Medeiros Florentino' \\ Eric Lucas dos Santos Cabral ${ }^{2}$ \\ Wilkson Ricardo Silva Castro ${ }^{2}$ \\ João Florêncio \\ da Costa Junior (1D ${ }^{3}$ \\ João Gomes de Torres Neto ${ }^{2}$ \\ Francisco de Cássio \\ de Oliveira Mendes (iD ${ }^{4}$ \\ Helio Roberto Hekis (D) $^{5}$ \\ Amália Cinthia Meneses Rêgo ${ }^{6}$ \\ Irami Araújo Filho $\mathbb{B}^{7}$ \\ 'Logistics and Hospital Infrastructure \\ Division, Graduate Program in \\ Production Engineering, UFRN, Natal, \\ Brazil; ${ }^{2}$ Department of Production \\ Engineering, Graduate Program in \\ Production Engineering, UFRN, Natal, \\ Brazil; ${ }^{3}$ School of Applied Social Sciences, \\ Education, Arts and Humanities, Laureate \\ International Universities (Potiguar \\ University), Natal, Brazil; ${ }^{4}$ Diagnostic \\ Imaging Unit and Graphic Method, \\ Graduate Program in Health Management \\ and Innovation, UFRN, Natal, Brazil; \\ ${ }^{5}$ Department of Biomedical Engineering, \\ Graduate Program in Production \\ Engineering, UFRN, Natal, Brazil; \\ ${ }^{6}$ Graduate Program in Biotechnology, \\ Laureate International Universities \\ (Potiguar University), Natal, Brazil; \\ ${ }^{7}$ Department of Surgery, Graduate \\ Program in Health Management and \\ Innovation, UFRN, Natal, Brazil
}

Correspondence: Irami Araújo Filho

Tel +55 $8498876-0206$

Fax + 5584 3342-5079

Email irami.filho@uol.com.br
Purpose: The hospital is an organization that has its own characteristics that differentiate it from other institutions. It is characterized as a company providing services of social purpose, with a great operational complexity, due to the diversity of services provided. These organizations are dependent on technology to play the role of assisting society. Technology is onerous: it is up to the aforementioned institutions to adopt management tools to control these costs. The present study explains the process of implementing a shared service centre (CENTROMED) for the management of hospital medical equipment (HME) at the Hospital Universitário Onofre Lopes (HUOL) in the city of Natal, RN.

Patients and Methods: In order to achieve a successful implementation, four key steps were taken: process modelling; determination of key performance indicators, organization of physical arrangement; and adequate training and development of human resources. The work followed an action research approach focusing on three main methodological steps: identification of HUOL clinical engineering team's demands, definition of the process for providing the equipment service, and definition of the supply items that will be managed.

Results: The preliminary results of this research indicate that the centralization of the management of the HME contributed to the optimization of the processes, the reduction of the costs and the availability of the equipment, thus providing a powerful management tool to support the hospital operational management.

Conclusion: The utilization of the shared service center for the management of hospital medical equipment is ultimately linked to the patient's well-being as it contributes to the agility in hospital procedures and provides support in maintaining the capacity of attendance of the assistance teams.

Keywords: hospitals, shared services center, hospital equipment and supplies, hospital maintenance and engineering, health services administration

\section{Introduction}

The State of Rio Grande do Norte has an area of 52,796.791 km2 with an estimated population of 3,228,198 inhabitants. The city of Natal is the capital and largest city of the state, with a population of 877,740 inhabitants, its metropolitan area consists of nine municipalities mainly the cities of Parnamirim, São Gonçalo do Amarante, Macaíba e Extremoz, totalling 1,485,505 inhabitants. ${ }^{1}$

The Hospital Universitário Onofre Lopes (HUOL) is a reference hospital and serves the entire population of the municipality of Natal and the metropolitan area, as well as patients from the countryside requiring medical attention through the 
Unified Health System - SUS. It is a teaching hospital, so users can be attended by Residents (Medical Residency or Multi-professional), but always under the supervision of a professor or preceptor responsible for the area.

Until the year of 2013 HUOL was characterized as one of the Supplementary Units of the Universidade Federal do Rio Grande do Norte (UFRN), a situation that ever since has changed with the adhesion to the Empresa Brasileira de Serviços Hospitalares (EBSERH), created through the Law 12,550/2011, so that the management of HUOL was carried out by this public company.

According to the latest public document issued, dated May 2013, HUOL has more than 300 beds, distributed amongst the following types: surgical clinic, medical clinic, psychiatry and isolation. The Hospital staff is currently composed of 531 civil servants from UFRN and 1,073 civil servants from EBSERH.

It is a well-established fact that Health Care Institutions (HCIs) have a relevant role in society due to their commitment to the treatment and cure of diseases. Technological advances contribute to the fulfilment of their prerogative, as the progress in technology increases health care effectiveness. ${ }^{2-4}$

The integration of new technologies generates considerable financial impact, which often is beyond the HCIs' financial capability. Resources - financial and otherwise are limited and need to be balanced with other deployments just as essential as the acquisition of new equipment, such as but not limited to: (a) the purchase of medicines, (b) payroll, (c) payment of suppliers, (d) maintenance costs, (e) admin costs. Hence, there is a significant effort on the part of managers to achieve cost reduction whilst new technologies and medical treatments emerge. ${ }^{3}$

Several HCIs cut costs by limiting the access to their services or by increasing the waiting time for care ${ }^{4}$ Hospital managers in several countries such as the United States are seeking alternatives to circumvent the financial problem and improve the quality of their services. ${ }^{5}$

In Brazil, based on a constitutional principle, the population has the right to free and ample health care access, which is a duty of the State. However, even considering the pertinence of this constitutional right, pragmatic questions arise as to whether the necessary resources to support such right exist and what would be their limits. ${ }^{2}$

The high demand for quality hospital services as well as patient safety leads to high investments in team building, processes refinement and modern equipment. ${ }^{6}$ Furthermore, compliance to government regulatory requirements and competitive issues are examples of the challenges faced by HCIs. ${ }^{7}$

Even though such circumstances may be ingrained in daily routine of hospitals, the management of health care organizations have other urgent aims than reducing costs and increase operational efficiency; which are not the only aspects necessary to provide effective health care for the population. ${ }^{8}$ Hospital management, therefore, has to concentrate its efforts into optimizing patient care, which implies in maintaining or restoring the patient's health. ${ }^{9}$ According to Machline and Barbieri ${ }^{10}$ specifically in hospitals, materials handling plays a significant role; hence, their efficient management has become imperative.

As a result of such reality, it is urgent to streamline hospital processes, taking into account speed and efficiency in communications to acquire, store and distribute materials and medicaments that are vital to patients' treatment. $^{11}$

According to the Brazilian Federation of Hospitals, ${ }^{12}$ approximately 4,810 hospital units attend the SUS, of which 807 are private, 1,665 philanthropic and 2,338 public. Amongst the philanthropic hospitals, the Santas Casas de Misericórdia - which account for more than $50.5 \%$ of outpatient visits and hospitalizations performed in the SUS - represent $43.1 \%$ of hospital beds in the country.

The Hospital Universitário Onofre Lopes (HUOL) which belongs to the Universidade Federal do Rio Grande do Norte (UFRN) and has been affiliated to the Empresa Brasileira de Serviços Hospitalares (EBSERH) since 2013 by a managerial contract, can be classified as a Philanthropic Hospital. The HUOL has a total area of $31.569,45 \mathrm{~m} 2$, offering 242 beds, with 24 intensive care units (5 paediatric and 19 adult patients), 84 outpatient clinics and 12 operating rooms. ${ }^{13}$

On a close analysis of HUOL routine activities, it was noticed a visible lack of HME managerial operations and regulations. Hence, it was decided that remodelling the HME management process was necessary as to properly address all demands whilst minimizing equipment downtime.

The present article describes the implementation process of a shared service centre to manage the hospital medical equipment at the Hospital Universitário Onofre Lopes, focusing on four mains stages: (1) analysis of the demands for medical and hospital equipment from the health care teams; (2) definition and structuring process of the physical environment for the CENTROMED 
implementation; (3) development of managerial and operational procedures for the CENTROMED activities; (4) establishment of best practice for training and development of the technical and support teams at CENTROMED.

\section{Background}

The need for organizations to remain competitive leads to a constant search for efficiency and cost reduction. Innovative organizations acquire competitive advantages through flexible and adaptable organizational structures. ${ }^{14}$

An organization model that has become popular in the mid-nineties is the shared service centre (SSC) in which the non-essential activities of the business units are concentrated. These activities thus become services that are delivered to the business units by a service unit. ${ }^{15}$ The SSCs are an organizational arrangement to supply services; which throughout their development have to face several challenges that may impact their final results. ${ }^{16}$

SSC are internal arrangements that distinguish and centralize the activities into a semi-autonomous unity. It follows the premise that services provided to a local department can be extended to a different one with relatively little extra effort. The SSCs allow the standardization, streamlining and consolidation of support functions from many different agencies in an autonomous organization aiming at supplying services seamlessly. ${ }^{17,18}$

Recent literature is composed of a wide variety of SSC definitions and attributes. Nonetheless, some conceptual aspects are common amongst the different sources, specifically a shared delimitation of the simple centralization concept whilst differentiating SSCs from traditional outsourcing companies. Furthermore, virtually all definitions point out to the advantages and improvements expected from the SSC approach. ${ }^{19}$

The expression "shared services" can be defined as the concentration of a given organization resources performing activities to attend to multiple internal partners, which comes alongside the standardization and consolidation of resource redundancy. Within the public-sector context, the concept encompasses the centralization of administrative services provision. ${ }^{20}$

As with outsourcing, the SSC model can generate economy of scale alongside the opportunity to furthering cost control both on labour and infrastructure in areas in which work physical location is not a critical element. Usually that means the replacement of relatively expensive workers in developed countries for less expensive labour in developing countries. ${ }^{21}$
Shared Service Centres (SSCs) have increased significantly in relevance and importance in recent years in the private sector as well as in the public sector. Public agencies make use of the SSC concept to reduce costs, improve the value of the service they offer, and achieve greater administrative efficiency. In many countries, many SSCs have already been established in the public sector. ${ }^{19}$

A service system includes people and information systems. Sharing service arrangement is a part of the service system in which a responsible semi-autonomous unit is created and provides predefined services specific to the operational units within the organizational entity. ${ }^{22}$

The decision to establish SSCs is normally case-based, showing the long-term costs and benefits of economies of scale and expertise compared to the current situation, often fragmented, without taking into account the implementation process. ${ }^{16}$

The literature on management sciences has explored in detail the economic and financial gains that can be expected through the implementation of SSCs, emphasizing improvement in the quality of services, as well as economies of scale caused by mutualisation and standardization. ${ }^{23}$

Overall demands to improve service delivery/quality and reduce costs have led many public organizations to develop managerial responses to enable the creation of Shared Service Centres. SSCs allowed the standardization, agility and consolidation of the support functions of various sectors in an autonomous organization with the singular objective of providing services in the most efficient and effective way possible. ${ }^{17,24}$

Shared Service Centres (SSCs) concentrate on nonstrategic administrative and support processes for the core organizational activities. That is, Shared Service Centres (SSCs) are internal units of an organization that provide services to other key organizational areas. Considering the specific characteristics and objectives of SSCs, it is necessary to develop specific managerial competencies for their management. ${ }^{25}$

SSC's business model is a compelling trend to public administration because resources are scarce, especially budgets and experience (intellectual capital); thus, efficient services cannot always be provided by an organization or department; especially if they are smaller public organizations that cannot incur the costs necessary to develop information services or systems. Furthermore, both small and large organizations have many types of knowledge that cannot be accessed beyond organizational boundaries. 
Shared services can provide access to specialized knowledge that is commonly out of reach. ${ }^{22}$

The search through the databases containing qualified articles indicated that there are few specific works that deal with the application of the idea of Shared Services Centre in hospital organizations: Griffin and Adams; ${ }^{26}$ Ratz, Chenoy and Morrison; ${ }^{27}$ as well as Batista, Alcântara and Paula. ${ }^{28}$ The former presents in detail ideas that align with the proposal to create a Shared Services Centre for hospitals, as they recommend the centralization of the supply of mechanical ventilators to patients inserted in the hospital environment.

\section{Methods}

Given the complex nature of the task involving the implementation of a shared service centre at a large hospital, which encompasses not only large-scale changes of processes but also the development of detail-oriented practices to reach maximum efficiency; the method of action research was selected by de authors as the most adequate procedure to ensure a seamless progression of the research at all predetermined stages.

The authors followed the reasoning of Thiollent ${ }^{29}$ who characterizes the action research method as a social research which is conceived and developed closely associated to an action of a collective problem resolution, in which the researchers as well as other relevant stakeholders are interrelatedly immersed in the circumstances studied. The research was thus developed based on a four stages model which highlights the necessary initiatives adopted throughout the implementation of the Medical Equipment Centre (CENTROMED) at the HUOL.

- Stage one: Demand identification.

It was identified alongside the HUOL clinical engineering the type of assistance needed in relation to hospital medical equipment in order to understand the requests for supply of items of the technologic park mainly for the ICUs, Surgical Centres, and Infirmary. Thereafter, based on Griffin and Adams, ${ }^{26}$ Ratz, Chenoy and Morrison ${ }^{27}$ as well as Batista, Alcântara and Paula, ${ }^{28}$ it was discussed how to further elaborate actions plans to reduce further investment in equipment acquisition.

- Stage two: Process definition.
The second stage comprises the definition of processes to structure the equipment sharing service coordinated with pre-established requisites and according to the conditions of the hospital (operational restrictions). Subsequently, the equipment flow diagram of the equipment plant was defined, with special attention to macro process of loan repayment and transportation of equipment.

- Stage three: Resources management policies. This stage was divided into six interdependent steps:

(A) Definition of the equipment to be managed at the HUOL hospital equipment centre, which included Monitors, Oximeter, Mechanical Fans, Electrocardiogram machine and monitors.

(B) Delineation of the employees to comprise the plant as well as their qualification requirements as it will be required the realization of equipment conformity tests - so far four electronic technicians in and one nurse were deemed necessary.

(C) Predefinition of equipment to be involved in the compliance.

(D) Determination of the necessary physical arrangements for the CENTROMED taking into account the need for workflows that favour routine actions within the equipment plant.

(E) Development of a protocol for the continuous verification of damages to equipment (from the quality tools Check Sheet, Stem-and-leaf display, Pareto Charts and Histograms).

(F) Establishment of indicators to delineate the scenario of equipment requirements.

- Stage four: Definition of workflows

Based on the controls and traceability of the items of the technologic park as to ensure the adequate handling and delivery of the equipment loaned; thenceforth, to map the actual hospital demand with respect to the loan service so that all applicants must carry out a searching in the equipment centre, as determined by EBSERH operating standard.

\section{Results}

In the study hospital of this article, it is found the Logistics Division and the Hospital Infrastructure (DLIH). One of the DLIH duties is to manage the hospital's technologic park and ensure the technological apparatus for the routine 
activities of the hospital units. Another relevant activity performed by DLIH is to ensure the supply of drugs, materials and utensils that are necessary for the operative procedures, clinical exams, laboratory tests and patient care.

Regarding the management of the technologic park, it is the DLIH responsibility to evaluate the need to purchase medical equipment, taking into account the cost restrictions of the hospital unit. From such evaluation, the equipment centre proposal stands out as an alternative to the equipment loan management so that it is possible to guarantee the assistance demands without the need to commit new resources in the equipment acquisition.

Therefore, we endeavour to make explicit the last months results following the CENTROMED implementation identifying the advances that need to be preserved and the opportunities for improvement that need to be addressed. Figures 1 and 2 show results associated with loan management of the Equipment Centre since its implementation in June to December 2018. The information catalogued below was obtained from the MV systems software.

Figure 1 shows the percentages of non-adherence of the months in which CENTROMED was implemented. The most representative percentages of non-adherence occurred in August, October and December. The lack of adherence to the system compromises the indicators of the Equipment Centre which in turn makes difficult the procedure of managing the resources of the services to units that have greater need.

The significant difference found in November and December in relation to the adherence is perhaps due to the reduction of management controls, which were circumvented in November through managerial meetings focused on team empowerment and high adherence maintenance. According to Figure 2, the most representative contribution to non-adherence in relation to the $\mathrm{MV}$ system is portable X-ray equipment.

The indicator shows that the improvement in adherence is owed to the need to improve the portable X-ray transport activity. It is evidenced from Figure 2 a discrete growth trend in non-adherence from that service.

Figure 3 shows that the amount of loans remains in a stable range throughout the evaluated months. The months of December and November stand out, respectively, as the highest and lowest occurrence of loans in the series evaluated. Stability in loan numbers is a decisive factor to predictability in the planning of CENTROMED operations.
Figure 4 displays the main operations performed by CENTROMED. The behaviour of this indicator shows regularity in the operations that occur throughout the period, thus facilitating the organization and planning of the service. Transportation is the service that is more representative in relation to the other services provided by the Equipment Centre.

It is necessary to make the following distinctions:

- Loans occur when CENTROMED makes available its own equipment so that another sector of the hospital can utilize it.

- Transportation is the movement of equipment, not owned by the plant, from one sector to another due to the need of assistance.

- Return is the collection of hospital medical equipment owned by CENTROMED.

- Repair is any activity related to fixing the equipment loaned.

- Replacement is the installation of a new piece of equipment due to the impossibility of repair.

Figure 5 addresses the relationship between the numbers of loans versus returns. It is expected that the amount of loans would be equal to the amount of returns, but in the figure, there is a significant discrepancy between those numbers. The month of December 2018 presents a greater discrepancy, since it is possible that this result is correlated to the low adherence to the system, corresponding to Figure 1.

The divergence between those figures indicates operational difficulties, compromising the attendance to new demands of loans due to the reduction of the equipment available. Figure 6 displays the behaviour of the service request frequency by equipment.

In Figure 6, the stability of CENTROMED attendance is evidenced, the variations are explained by the seasonality of the medical demands in the period. The equipments that are offered in the loan service are: infusion pump, electrocardiograph, multiparameter monitor and fan; the transport services are in relation to the following equipment: Portable $\mathrm{X}$-ray and haemodialysis machine.

Depending on the nature of the demand, the ultrasound equipment can be requested as a loan or transportation service, that is, if the demand is a specific need, the requested service will be transportation, since the equipment owned by CENTROMED meets the general use criteria.

In the loan service, the emphasis is on infusion pumps. At HUOL there are 30 such equipment available at the equipment 
centre, the results presented in the month of July were a consequence of this technology incorporation at the end of the month. In the transportation service, the request of haemodialysis machines is highlighted as the demand is exclusive in the care of the ICU, reflecting the clinical conditions of the hospitalized patients. In Figure 7 the discussion about the sectors that demand services from CENTROMED is carried out.

In Figure 7 it is evident that the ICN is the main user of the equipment centre. This result corroborated with managerial expectations, as the wards are not technologically equipped to perform specific treatments such as respiratory failure, for instance, when ventilatory support is required for the patient clinical support.

Figure 7 indicates that the clinical profile of patients who are selected for care in the HUOL presents variations that are indicative of the necessity to restructure HUOL operations, focusing on the acquisition of hospital medical equipment, improvement of the screening of patients who are admitted and assurance of patient care capacity. It is also highlighted the requests for medical equipment from the Adult ICU, so that, according to Figure 6, there was a request, especially in relation to the Haemodialysis Machines, which indicates changes in the clinical conditions of the patient.

Such results are an indication that the hospital spaces destined to patient care should be the object of discussion in the coming years due to changes brought about by new demands related to medical care, which will undoubtedly lead to infrastructural changes related to the incorporation of new technologies in the HUOL technologic park in order to meet these demands.

In the space corresponding CENTROMED, the following processes are carried out:

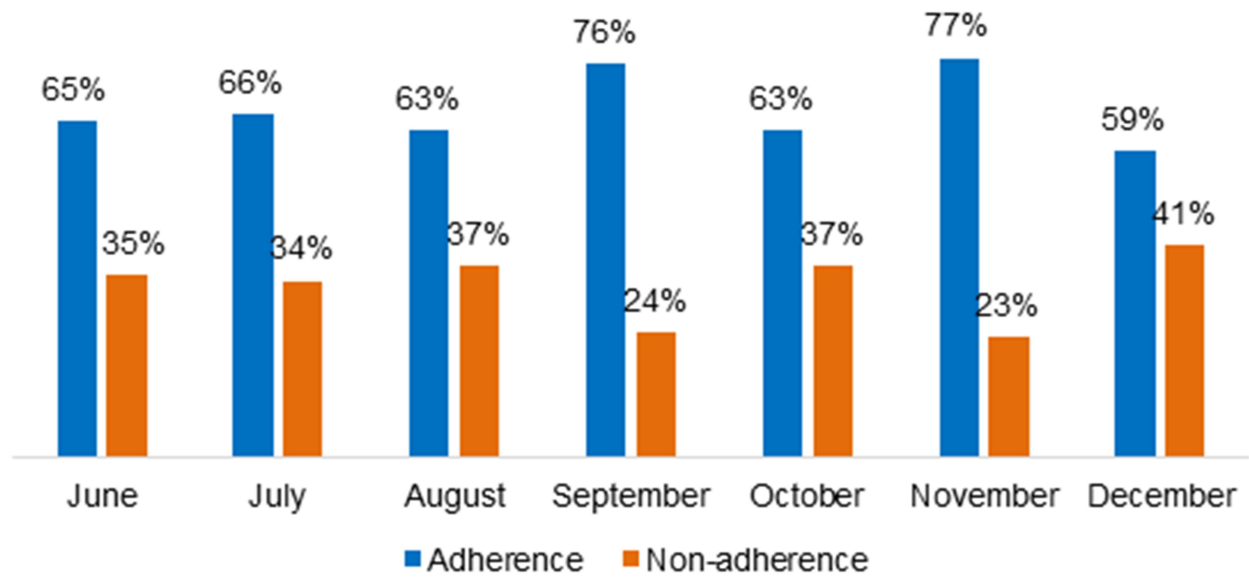

Figure I Adherence and non-adherence to the loan management system (MV systems).

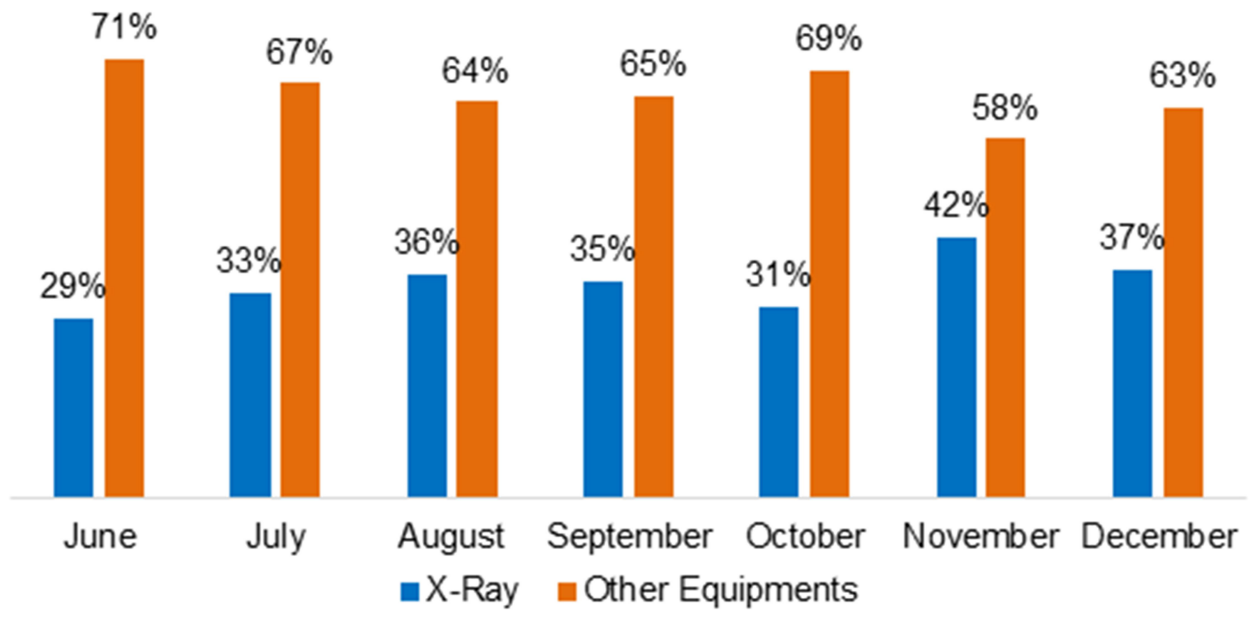

Figure 2 Relevance of X-ray in non-adherence. 


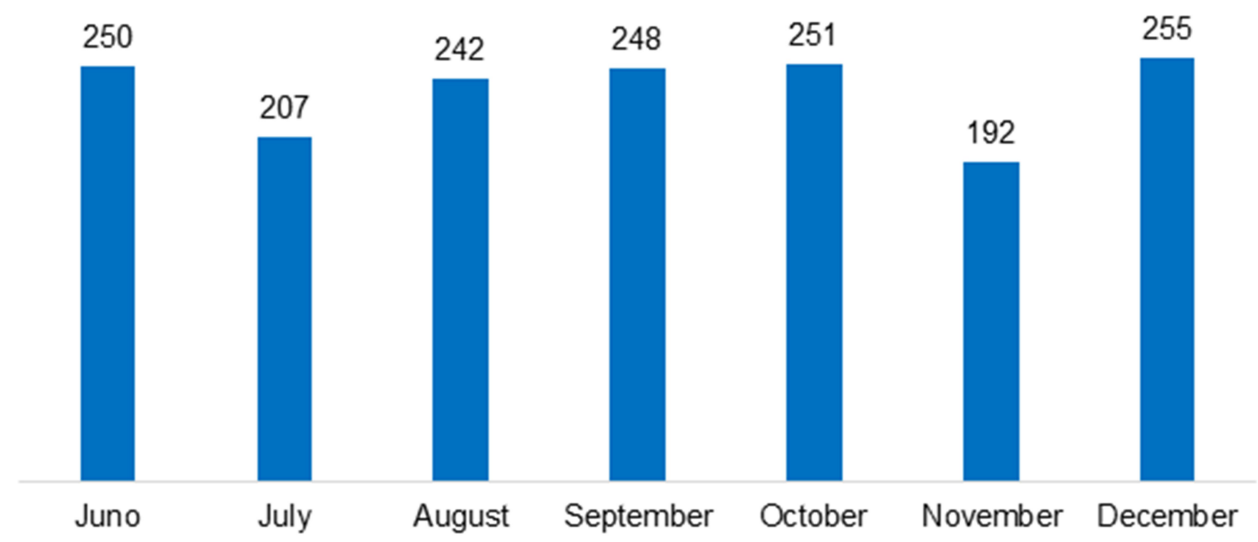

Figure 3 Monthly quantitative loans.

- The equipment hygiene.

- The equipment availability tests.

- The repair of the equipment in case of asset unavailability.

- The effective storage of the HME for service requests.

Some of the equipment managed by CENTROMED are shown in Table 1.

Table 1 shows the Multiparameter Monitor, Electrocardiograph, Mechanical Ventilator, Oximeter and Ultrasound monitors. The need for such equipment is discussed in Figures 4 and 6.

\section{Discussions}

The idea of implementing an equipment centre at HUOL was conceived from a technical visit promoted by the hospital management at the facilities of the Hospital
Universitário at the Universidade Federal de São Paulo (UNIFESP) in 2013. During the visit, management initiatives were analysed and then proposed to the HUOL Clinical Engineering Sector in order to modernize the management of medical and hospital equipment. The internal demand from some sectors to request medical-hospital technology for routine procedures was seminal for the idea to gain scope.

The diagnostic evaluation through the monitoring of the Clinical Engineering Sector operations confirmed that there was a request for equipment purchase superior to the institution financial means. Some sectors showed a tendency to mishandle equipment which resulted in the non-attendance of the requisitions, compromising the technological infrastructure necessary for patient care.

Loans is procedure utilized to request the use of hospital medical equipment, usually intermediated by a health management system (MV Systems, for instance). When

- Loans 39\% = Transportation 46\% =Devolution 12\% = Repair $2 \% \quad$ - Replacement $1 \%$

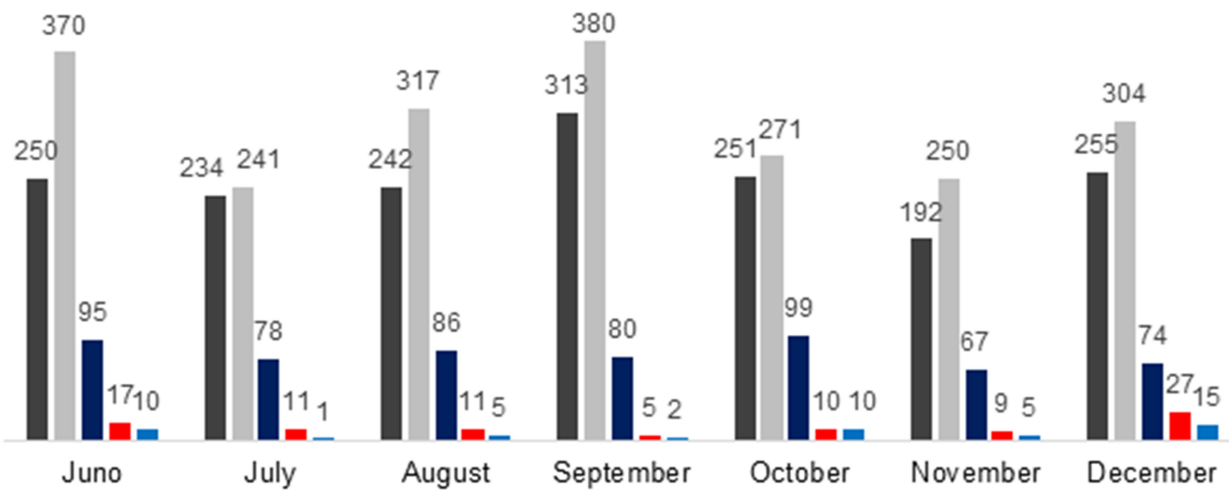

Figure 4 CENTROMED activities distribution. 


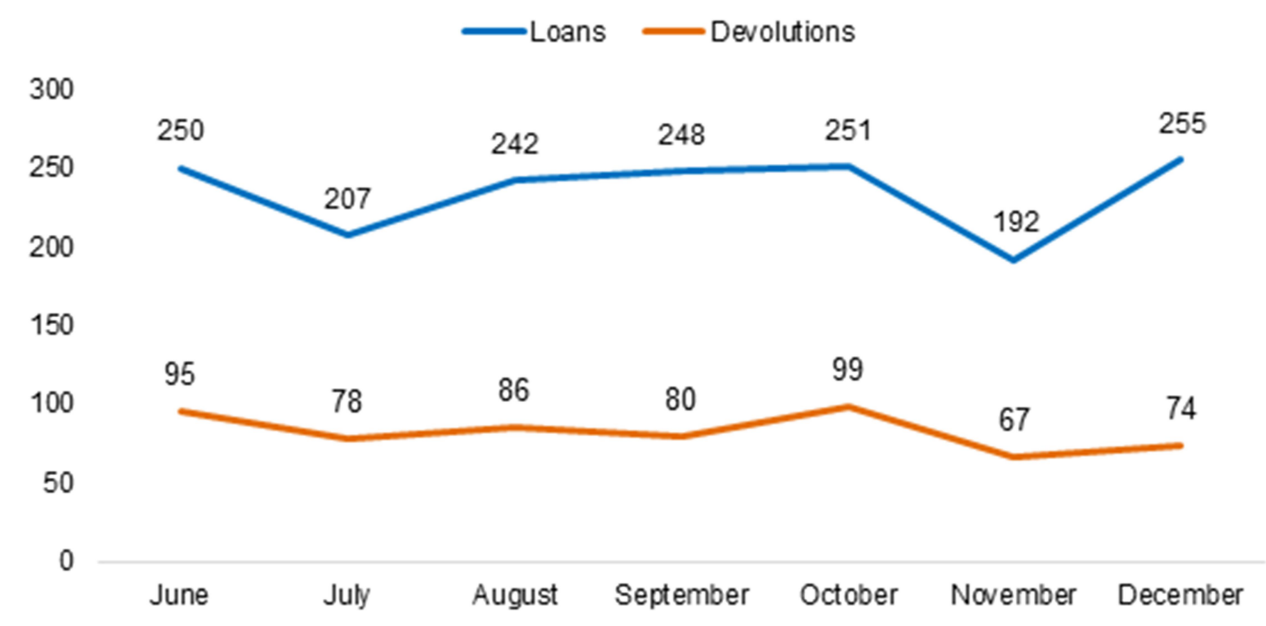

Figure 5 Loans and returns figures.

some equipment receives a loan request, the Equipment Centre (CENTROMED) has to manage the process, checking the equipment availability as to optimize its deployment and maintainability. Such requests are commonly targeted: Multiparameter Monitors, Fans, Oximeters and Electrocardiograms (ECG).

The loan of equipment between the sectors occurred regularly to meet the demand; resulting in a procedure that did not take into consideration the proper handling and maintenance of the equipment, the item of the technological park in some situations was damaged and its traceability inside the hospital was compromised.

Transport is procedure for medical equipment shifts in hospital facilities, usually performed by a professional with a technical graduation in electronics. Some critical items in the hospital technology park may require this operation such as Portable X-Ray, Ultrasound, Echocardiogram, Endoscopy Tube, Endoscopy Tower and Intra-aortic Balloon.

The Clinical Engineering sector in this context did not present any solutions to those issues, which compromised the care services quality perception. Although there were some requests in this direction to the sector, it was not within its remit to solve such problem. The implementation of CENTROMED centralized these requests.

Following the solutions presented in this article, the requisition of hospital medical equipment started to reveal distinctive changes, such as: (1) equipment requisition via

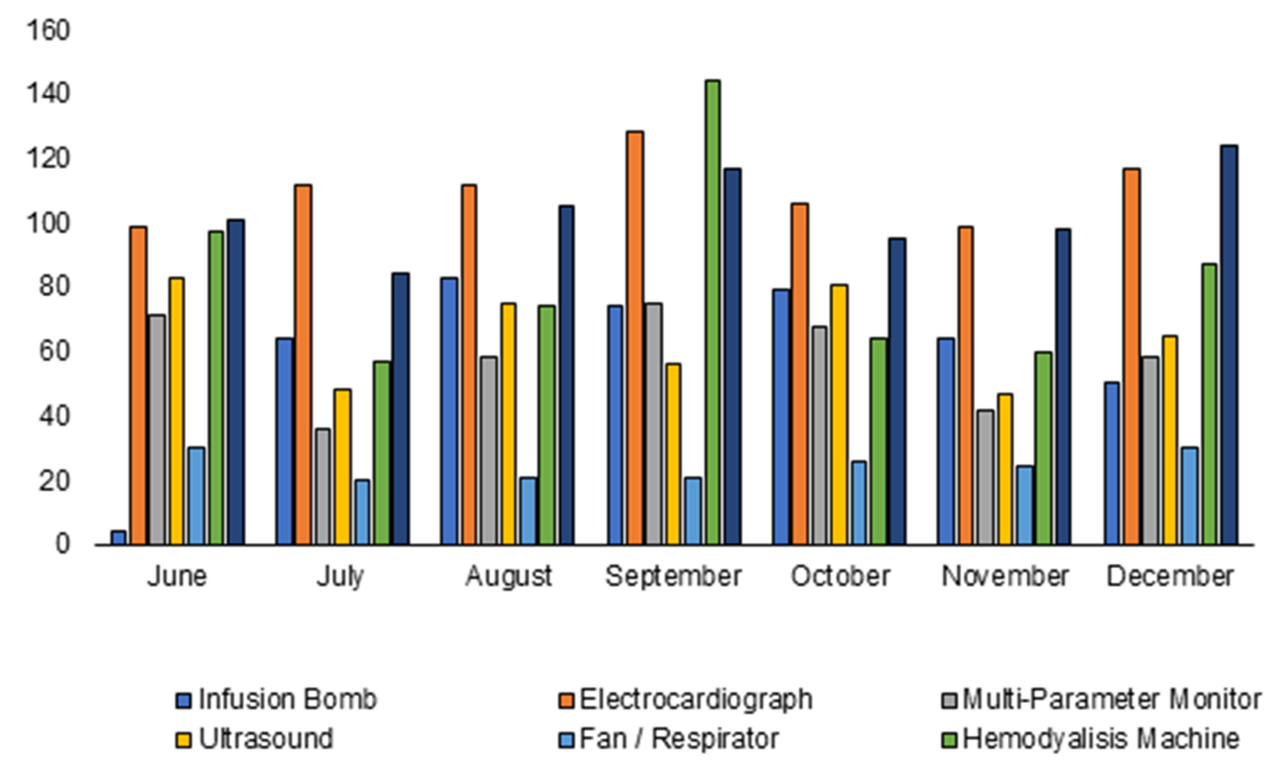

Figure 6 Frequency of service request (transportation and loans) per equipment. 


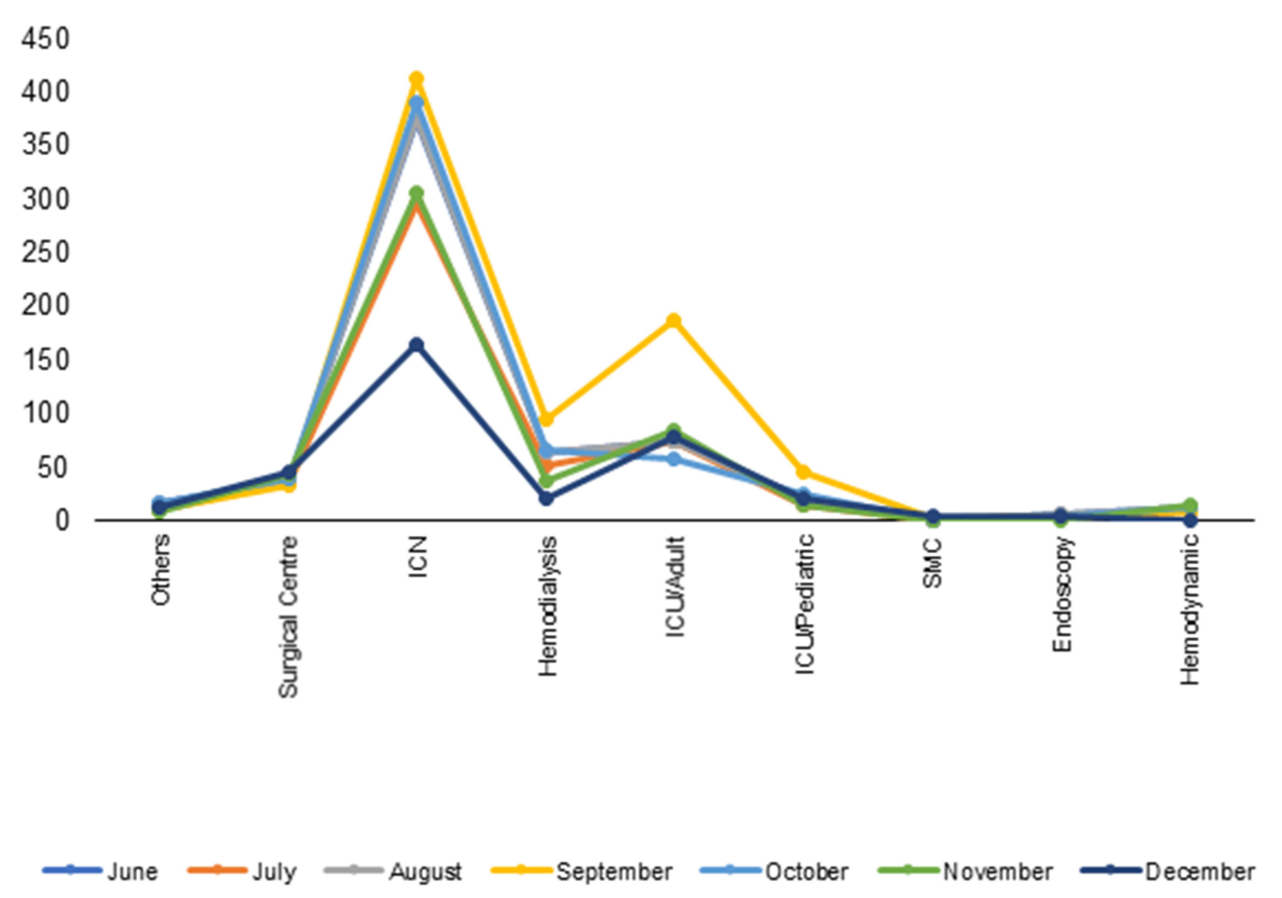

Figure 7 Sectors that solicit equipment to CENTROMED.

a system of creation of order drivers (workshops); (2) technology requests to some sectors have been met (requests from the Central Building of Internment, for instance) by loan; (3) cleaning and testing (functional tests) occurred prior to making the equipment available for use; (4) presentation of operational performance indicators in monthly meeting focusing on traceability, adherence, requisition and service of adequate transportation of technology between sectors.

The results of the loan of the infusion pump in the month of June 2018 were caused because in that month the technology was incorporated in the equipment centre park. Before that month, the administration of the infusion pumps was performed by the Pharmaceutical Supply Unit. The transference of this technology to CENTROMED made it possible to manage this equipment properly. The results of transport of the haemodialysis machine in September 2018 resulted in a significant increase in requests for this equipment by the haemodialysis service for the Intensive Care Unit.

Prior to the formation of CENTROMED, the haemodialysis machines transportation was performed by the dialysis service itself or the ICU patient was conducted the facilities of this service. The offer of the transportation service provided by CENTROMED provided greater comfort to the maintenance team and adequate patient care.
Based on this study, such information system presents inadequacies that affect the operations of CENTROMED, as it does not offer modules compatible with the operations performed. Some of these inadequacies obstruct the management decisions of the internal users of the hospital, given that this system does not allow the visualization of the unavailability of the service in the act of the request as it is not possible to register the items of the technologic park, being limited to register the requests that should be executed.

CENTROMED's performance information management has to be linked to the collection of the daily fulfilment of the service procedure performed by the central plant. Thus, monthly meetings are held with the technical team as well as managerial meetings whenever necessary, with the maintenance team. In relation to the monthly meetings, there are perceptions of evolution and exposure of improvement results.

Throughout these meetings, taking into account the needs for CENTROMED improvement actions, the corrective measures that should be implemented are presented. When corrective measures need to involve other sectors, resolution is given through management meetings (coordination of CENTROMED with the Health Hospitality Team, Assistance Team, Administrative Management, Superintendence, Process Management Sector and Information Technology Sector). 
Table I Some Items Managed at CENTROMED

\begin{tabular}{|c|c|c|c|c|}
\hline Code & Equipment & Patrimony EBSERH & Manufacturer & Model \\
\hline CEQ ECG - 0I & Electrocardiograph & 187.130 & DIXTAL & EP-3 \\
\hline CEQ ECG - 03 & Electrocardiograph & 195.055 & DIXTAL & EP-3 \\
\hline CEQ ULT - OI & Ultrasound & & GE & LOGIC E \\
\hline CEQ OXI - OI & Oximeter & 195.627 & CMOS DRAKE & OXILIFE PLUS \\
\hline CEQ OXI - 02 & Oximeter & 195.626 & CMOS DRAKE & OXILIFE PLUS \\
\hline CEQ VMP - 06 & Mechanical Fan & 188.369 & DIXTAL & $D \times 3010$ \\
\hline CEQ VMP - 07 & Mechanical Fan & 2008047806(HOSPED) & DIXTAL & $D \times 3010$ \\
\hline CEQ VMP - 08 & Mechanical Fan & 2008047809(HOSPED) & DIXTAL & $D \times 3010$ \\
\hline CEQ VMP - 09 & Mechanical Fan & 2008047804(HOSPED) & DIXTAL & $D \times 3010$ \\
\hline CEQ VMP - 10 & Mechanical Fan & 2008047807(HOSPED) & DIXTAL & $D \times 3010$ \\
\hline CEQ VMP - II & Mechanical Fan & 2008047808 & DIXTAL & DX 3010 \\
\hline CEQ VMP - 12 & Mechanical Fan & 1501563 & INTERMED & INTER 5 PLUS \\
\hline CEQ VMP - 13 & Mechanical Fan & 0501565 (UFRN) & INTERMED & INTER 5 PLUS \\
\hline CEQ MMP - OI & Multiparameter Monitor & $2013018831($ UFRN) & OMNIMED & OMNI6I2 \\
\hline CEQ MMP - 02 & Multiparameter Monitor & 188.384 & OMNIMED & OMNI6I2 \\
\hline CEQ MMP - 03 & Multiparameter Monitor & 188.035 & OMNIMED & OMNI6I2 \\
\hline CEQ MMP - 04 & Multiparameter Monitor & 188.965 & OMNIMED & OMNI6I2 \\
\hline CEQ MMP - 05 & Multiparameter Monitor & 188.387 & OMNIMED & OMNI6I2 \\
\hline CEQ MMP - 06 & Multiparameter Monitor & 194.980 & OMNIMED & OMNI6I2 \\
\hline CEQ MMP - 07 & Multiparameter Monitor & 186.783 & OMNIMED & OMNI6I2 \\
\hline CEQ MMP - 13 & Multiparameter Monitor & 503032 & DIXTAL & DX 2010 \\
\hline CEQ MMP - 14 & Multiparameter Monitor & 194955 & DIXTAL & $D \times 2010$ \\
\hline CEQ MMP - 15 & Multiparameter Monitor & 194208 & DIXTAL & DX 202I \\
\hline
\end{tabular}

The results achieved motivated the Communication, Security and Transportation Service linked to the Physical Infrastructure Sector to replicate the procedures abovementioned to resolve another bottleneck inherent to the hospital's internal processes: labour deficit to transport the patients within the hospital.

Such replication provided satisfactory results to the Care Team and made the admissions to the current staff level more efficient. The Hospital das Clínicas de Pernambuco also developed an idea similar to the transport of patients from a technical visit at the HUOL facilities.

The Hospital Universitário of UNIFESP has a centre for equipment management similar to the proposed in the present study. In the Hospital Universitário of UNIFESP, the equipment centre carries out the following services: loan of equipment, availability of materials and preparation of operating rooms. In view of the HUOL scenario, it is not necessary for CENTROMED to perform the services of materials availability and preparation of operating rooms for the following reasons: there is a Material and Sterilization Centre responsible for material management and the clinical engineering sector maintains a technician fixed in the surgical centre responsible for the support of the surgical procedures.

There is a practice performed at HUOL facilities that should be the subject of discussion regarding the operations of CENTROMED: the transportation of X-ray equipment, haemodialysis machine and ultrasound machine is performed at UNIFESP by the care team. In the specific case of the HUOL, there is the understanding that it is necessary to guarantee to the assistance teams time availability for their core activities with patients instead of demanding time and effort for non-essential activities such as equipment transportation.

Furthermore, taking into account that the transportation of equipment involves the disassembly, transportation and assembly, activities that are compatible with the profile of maintenance professionals; there is a significant reduction in the risk of breakage when the equipment is transported by specialized professionals, making necessary to add this competence to CENTROMED.

Hence, it is relevant to discuss the sequencing rule committed to service requests made to CENTROMED. At the moment, the requests are fulfilled following FIFO rule (First In First Out). Except for life support equipment 
requirements such as mechanical ventilators, in which case, take precedence over the multi-parameter monitor.

The cost-effectiveness of public resources intended to the acquisition of hospital medical equipment is another positive consequence of the implementation of CENTROMED at HUOL. Before the present management model implementation, it was the assistance team practice to increase the technological park that attends the patients in the eight floors of the ECI.

Such acquisitions, totalling $\mathrm{R} \$ 2,443,000.00$ intended to incorporate to the technologic park 48 multi-parameter monitors, 8 electrocardiographs and 24 mechanical ventilators, and were since then reviewed due to the understanding that the real need will be met given the loan service offered by CENTROMED is effectively carried out. The equipment loan management promoted by this centre ensured that 8 multiparameter monitors, 2 electrocardiographs and 5 mechanical ventilators, which add up to amounts of $\mathrm{R} \$ 468,000.00$, were sufficient to attend all hospital floors without any loss of quality of care or prevarication in view of the institutional purposes of the hospital in serving the population demanding the medical service.

Furthermore, the planned daily operations of CENTROMED ensure continuity of clinical engineering services on weekends; such work routine ensures that clinical tests, for instance, are continuously carried out, supporting the increasing of hospital capacity, especially in critical areas such as Intensive Care Unit beds wherein an eventual equipment breakdown without prompt repair results in the closure of the bed and compromises the capacity of attendance of the assistance teams.

\section{Conclusions}

According to what was established in the problematic of this study, there is a requirement of agility in the hospital procedures taking into account that the criteria of performance speed and efficiency in the communication for acquisition, storage and distribution of materials and medicines are ultimately linked to the patient well-being. Hence, the change in users' clinical profile at HUOL also makes necessary changes in the technological apparatus that should support the procedures of the assistance teams. The financing model of hospitals in the EBSERH network (to which HUOL is a subsidiary) is based on budget, which demands economy in the use of the resources committed to health services.
In this scenario, there are many interrelated actions that can be taken to address the multifaceted requirements of quality and speed for the proper CENTROMED functioning: (1) adopting the shared service centre strategy to properly manage similar requests; (2) empowering the multidisciplinary team that coordinates and executes the work at CENTROMED through monthly meetings focusing on statistical data about key performance indicators; (3) elaborating action plans whenever deemed necessary to address the deviations against the established operational rigour.

Taking into account the current discussion, given the importance of the topic, it is considered necessary to stimulate the development of studies that seek to understand and measure the impact of the implantation of CENTROMED in hospital units in terms of costs, impact on patient care, impact on resources dimensions, impact on the perception of user satisfaction, impact on the appropriate use of hospital medical equipment as an asset maintenance strategy and the use of quality engineering tools to contribute to the assurance of asset availability when required.

Due to the extraordinary situation caused by the COVID-19 pandemic, the regulation of medical equipment deployment carried out by CENTROMED has followed the need for monitoring patients in the wards (a fact that is not common in the hospital routine), which indicates the necessity to analyse the effects of the pandemic on the procedures utilized in the present study to define the needs of equipment, particularly in the Equipment Centre.

Future works may also present software architectures for management of CENTROMED operations by developing management reports for decision support and control. The limitations of this work are related to the possibility of non-adherence of the main stakeholders involved in the service in view of the execution of requests through the MV system.

\section{Acknowledgments}

This study was financed in part by the Coordenação de Aperfeiçoamento de Pessoal de Nível Superior - Brasil (CAPES) -Finance Code 001. As this is a research that did not involve human beings (it is a descriptive study of the creation of a shared services center), there was no need for prior approval by a research ethics committee.

\section{Disclosure}

The authors report no conflicts of interest for this work. 


\section{References}

1. Instituto Brasileiro de Geografia e Estatística/Brazilian Institute of Geography and Statistics [homepage on the internet]. Demographic census. 2010. Available from: http:www.ibge.gov.br. Accessed December 17, 2018.

2. Kaiser R, Spiegel PB, Henderson AK, Gerber ML. The application of geographic information systems and global positioning systems in humanitarian emergencies: lessons learned, programme implications and future research. Disasters. 2003;27(2):127-140. doi:10.1111/ 1467-7717.00224

3. Moreno Junior JMP, Zucchi P. Avaliação de qualidade em serviços de saúde: acreditação, certificação e programas de melhoria da qualidade em hospitais públicos e privados do município de São Paulo. Rap. 2005;39(1):7-16.

4. Godfrey AB, Halder RB. ISQua position paper: a response improving health care quality. is standardization the answer? Int J Qual Health Care. 1997;9(5):339-340. doi:10.1093/intqhe/9.5.339

5. Herlinger H. Small bowel. In: Gore RM, Levine MS, editors. Textbook of Gastrointestinal Radiology. 3rd ed. Philadelphia: W.B. Saunders Co; 2007:735-806.

6. Ortiz Barrios MA, Felizzola Jiménez H. Use of six sigma methodology to reduce appointment lead-time in obstetrics outpatient department. J Med Syst. 2016;40(10):220. doi:10.1007/s10916-0160577-3

7. Damasceno HEM, Damasceno ARG, Pascoal A, De MFC. Aplicação da estratégia seis sigma à uma unidade de saúde/Application of the six sigma strategy to a health unit. 2005:1-6.

8. Souza PC, Gurtler Scatena JH, Kehrig RT. Eficiência Hospitalar No Sus: análise De 10 Hospitais Do Mix Público-Privado Do Estado De Mato Grosso/Hospital Efficiency in Sus: analysis of 10 hospitals in the public-private mix of the state of Mato Grosso. Cad Gestão Pública e Cid. 2017;22(72):335-354.

9. Moura A, Viriato A. Gestao Hospitalar: da organizacao ao servico de apoio diagnostico e terapêutico/Hospital Management: From the Organization to the Diagnostic and Therapeutic Support Service. Brazil: Manole; 2008.

10. Barbieri JC, Machline C. Logística Hospitalar: Teoria e prátical Hospital Logistics: Theory and practice. Brazil: Saraiva; 2009.

11. Kamimura QP, Cornetta VK, Bittar OJNV. Logística em serviços de saúde: estudo em um hospital público/Logistics in health services: study in a public hospital. Lat Am J Bus Manag. 2015;6(1):132-143.

12. Federação Brasileira de Hospitais/Brazilian Federation of Hospitals [homepage on the internet]. Public hospitals survey. Available from: http://fbh.com.br/. Accessed December 20, 2018.

13. Empresa Brasileira de Serviços Hospitalares (EBSERH)/Brazilian Hospital Services Company. Rede EBSERH/EBSERH branches. Available from: https://www.gov.br/ebserh/pt-br/acesso-a-informa cao/hospitais-universitarios-federais/rede-ebserh. Accessed October 25, 2018.

14. Richter PC, Brühl R. Shared service center research: a review of the past, present, and future. Eur Manag J. 2017;35(1):26-38. doi:10.1016/j.emj.2016.08.004
15. Minnaar RA, Vosselman EGJ. Shared service centres and management control structure change: exploring the scope and limitations of a transaction cost economics approach. J Account Organ Chang. 2013;9(1):74-94. doi:10.1108/18325911311307212

16. Knol A, Janssen M, Sol H. A taxonomy of management challenges for developing shared services arrangements. Eur Manag J. 2014;32 (1):91-103. doi:10.1016/j.emj.2013.02.006

17. Janssen M, Joha A. Motives for establishing shared service centers in public administrations. Int $J$ Inf Manage. 2006;26(2):102-115. doi:10.1016/j.ijinfomgt.2005.11.006

18. Harritz D. Role of management devices in enacting strategy - case study of shared service centre. J Account Organ Chang. 2016;12 (4):504-521. doi:10.1108/JAOC-02-2015-0023

19. Schulz V, Brenner W. Characteristics of shared service centers. Transform Gov: People, Process and Policy. 2010;4(3):210-219. doi:10.1108/17506161011065190

20. Niehaves B, Krause A. Shared service strategies in local government - a multiple case study exploration. Transform Gov: People, Process and Policy. 2010;4(3):266-279. doi:10.1108/1750616 1011065235

21. Rothwell AT, Herbert IP, Seal W. Shared service centers and professional employability. $J$ Vocat Behav. 2011;79(1):241-252. doi:10.1016/j.jvb.2011.01.001

22. Janssen M, Joha A, Zuurmond A. Simulation and animation for adopting shared services: evaluating and comparing alternative arrangements. Gov Inf Q. 2009;26(1):15-24.

23. Arnoud J, Falzon P. Shared services centers and work sustainability: which contributions from ergonomics? Work. 2012;41(Suppl 1):3914-3919. doi:10.3233/WOR-2012-0061-3914

24. Zeynep Aksin O, Masini A. Effective strategies for internal outsourcing and offshoring of business services: an empirical investigation. J Oper Manag. 2008;26(2):239-256. doi:10.1016/j.jom.2007.02.003

25. Santos MR, Rocha-Pinto SR, Guimarães MIP. Centros de serviços compartilhados: um estudo de caso sobre fatores intervenientes na formação de competências gerenciais/shared services centers: a case study about the intervening factors on managerial competencies building. Race. 2015;14(2):505-536. doi:10.18593/race.v14i2.6927

26. Griffin A, Adams S. Shared services - a recipe for cost-cutting in hospitals. Long Range Plann. 1981;14(6):76-79. doi:10.1016/00246301(81)90063-7

27. Ratz JE, Chenoy NC, Morrison MJ. Planning for shared services: lessons from experiences of the princess margaret hospital. Healthc Manag Forum. 1991;4(2):3-11. doi:10.1016/S0840-4704(10)61239-2

28. Batista MDA, Alcântara EC, Khellen L, De PG. Central de Ventiladores Mecânicos: organização, Segurança e Qualidade/ Central mechanical fans: organization, safety and quality. Rev Bras Ter Intensiva. 2007;19(4):450-455. doi:10.1590/S0103-507X2007 000400008

29. Thiollent M. Metodologia da pesquisa-ação/Action Research Methodology. 18th ed. São Paulo: Cortez; 2011.
Journal of Multidisciplinary Healthcare

\section{Publish your work in this journal}

The Journal of Multidisciplinary Healthcare is an international, peerreviewed open-access journal that aims to represent and publish research in healthcare areas delivered by practitioners of different disciplines. This includes studies and reviews conducted by multidisciplinary teams as well as research which evaluates the results or conduct of such teams or healthcare processes in general. The journal covers a very wide range of areas and welcomes submissions from practitioners at all levels, from all over the world. The manuscript management system is completely online and includes a very quick and fair peer-review system. Visit http://www.dovepress.com/testimonials. php to read real quotes from published authors. 